GEOPHYSICAL RESEARCH LETTERS, VOL. 1, NO . 9, PAGES 903-906, SEPTEMBER 1984

\title{
IONOSPHERIC CURRENTS AND F-REGION PLASMA BOUNDARIES NEAR THE DAYSIDE CUSP
}

\author{
S. Vennerstrom, ${ }^{1}$ E. Friis-Christensen, ${ }^{1}$ T. S. Jorgensen, ${ }^{1}$ O. Rasmussen, ${ }^{1}$ C. R. Clauer ${ }^{2}$ and V. B. Wickwar ${ }^{3}$ \\ 'Division of Geophysics, Danish Meteorological Institute \\ 2Space, Telecommunications and Radioscience Laboratory \\ Stanford Electronics Laboratories, Stanford University \\ ${ }^{3}$ Radio Physics Laboratory, SRI International
}

\begin{abstract}
Observational evidence of the location of a dayside high-latitude ionospheric current (DPY current) with respect to the different regimes of the high-latitude magnetosphere is obtained by analyzing data from the magnetometer chain along the west coast of Greenland in conjunction with simultaneous measurements from the newly established incoherent-scatter radar facility at Sondre Stromfjord. The latitudinal location of the DPY current is compared with the location of the maximum F-region electron temperature and with the location of the plasma convection reversal from sunward to antisunward. The maximum in the F-region electron temperature roughly coincides with the velocity reversal boundary, while the DPY current is always located more poleward, penetrating deep into the polar cap. When UT variations are examined, a correlation of 70 to 80 percent is found between the three locations.
\end{abstract}

\section{Introduction}

The DPY current flows generally east-west at high latitudes in the sunlit part of the ionosphere. It is known to change direction with the $B_{y}$ component of the interplanetary magnetic field (IMF) and is fairly easy to distinguish on the records of a chain of magnetometers at the proper latitudes.

Although extensive work has been done to describe the DPY current and its relationship to the IMF [FriisChristensen and Wilhjelm, 1975; Mishin et al., 1981; Feldstein et al., 1982; Troshichev, 1982; Friis-Christensen et al., 1984], the nature of the current and especially its relationship to the auroral zone electrojets is not yet fully clarified. Some hold the opinion that the DPY effect in the magnetometer records is caused by a redistribution of the electrojets [Rostoker, 1980] while others consider the DPY as a separate current, which can vary independently with respect to the auroral electrojets [Friis-Christensen, 1981; FriisChristensen et al., 1984].

In recent years a considerable effort has been directed toward identifying the field-aligned currents feeding the ionospheric DPY current [lijima and Potemra, 1976; Wilhjelm et al., 1978; Rostoker, 1980; Kamide, 1982; Troshichev, 1980; Friis-Christensen et al., 1984], but it has proved difficult to distinguish different magnetospheric sources because

Copyright 1984 by the American Geophysical Union.

Paper number 4L6202.

0094-8276/84/004L-6202\$03.00 of the complexity of the total field-aligned current system [e.g., Rich and Kamide, 1983; McDiarmid et al., 1979]. In the work reported here we approach the question of the origin of the DPY current from a somewhat different direction.

The incoherent-scatter radar in Sondre Stromfjord, together with the Greenland chain of magnetometers, makes possible simultaneous observations of the DPY current and other ionospheric parameters. We use such observations to examine the spatial relationship between the following three physical quantities:

- The poleward and the equatorward boundaries of the DPY current.

- The elevated F-region electron temperature, which is probably associated with soft electron precipitation in the cleft region [Wickwar and Kofman, 1984, and references therein].

- The reversal in the convection pattern from sunward to antisunward [Jorgensen et al., 1984, and references therein.]

\section{Observations}

The data we examined were obtained during a total of 50 hrs of observations in April and July 1983. The observational procedure followed was that described by Wickwar et al. [1984], although at times there were minor modifications. A more detailed description is found in Foster et al. [1981], Jorgensen et al. [1984], and Clauer et al. [1984]. In their reduced form, the radar data have a time resolution of about $20 \mathrm{~min}$ between consecutive measurements at the same latitude. From the newly reestablished magnetometer chain in Greenland, digital data are available with a sampling rate of $1 \mathrm{~min}^{-1}$.

The invariant latitudes of the poleward and equatorward boundary of the DPY current were determined by means of a method described by Kisabeth and Rostoker [1971]. The method is based on latitude profiles of the magnetic elements, especially the location of the extrema in the vertical component.

In Figure 1(a) are examples of the latitude profiles showing the DPY current location. One should be aware that the presence of an eastward or westward electrojet equatorward of the DPY [Figure 1(b)] can introduce systematic errors, particularly in the determination of the equatorward boundary. If the two currents are flowing in the same direction, the estimate of the latitude will be a little too high. If, on the other hand, the two currents are antiparallel, the estimated 


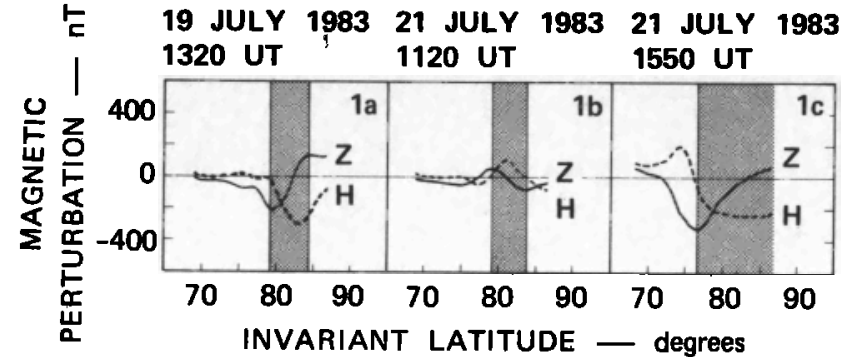

Fig. 1. Three examples of latitude profiles of the magnetic elements $\mathbf{H}$ (horizontal) and $\mathrm{Z}$ (vertical). The DPY current Indicated by the shaded area is located between the extrema in the $\mathrm{Z}$ component.

latitude will be a little too low. Since it is often - but far from always - difficult to identify a clear equatorward boundary of the DPY current when the two currents are unidirectional, the main part of the inferred latitudes consists of cases corresponding to two oppositely directed currents.

The boundaries - determined by means of the $\mathrm{Z}$ component - were only included in the study when the current was also clearly seen in the $H$ profiles and when the time variations in the normal magnetograms showed that the current was indeed a DPY current. In some cases, especially near the eastern or western border of the current, it is impossible to determine a poleward boundary because the current seems to broaden and extend beyond the latitudinal range of the magnetometer chain. Figure 1(c) provides an example.

\section{Results}

Figure 2 shows a contour plot of the F-region electron temperatures at an altitude of $\sim 350 \mathrm{~km}$. The latitudinal variation is plotted against UT. To make the temperature maxima more prominent, the high-temperature contours are drawn with a solid line, while the low-temperature contours are dotted. A region of elevated electron temperature limited in latitudinal extent stands out clearly.

Simultaneously with the electron temperature, the incoherint-scatter radar also measured the plasma velocity in the $\mathrm{F}$ region. The heavy dotted line shows the boundary between sunward and antisunward convection. The dots should not be confused with actual measuring points; they are on line segments that connect measuring points. In terms of the present understanding of magnetosphere-ionosphere coupling, this line indicates the boundary between the primary convection flowing across the polar cap, and the secondary convection or return flow. It is seen that the reversal boundary rather closely follows the region of maximum temperatures.

The shaded area in the figure represents the location of the DPY current determined by its equatorward and poleward boundary. The current is obviously located poleward of the convection-reversal boundary and the maximum in the electron temperature. Furthermore the UT variations in the latitude of all three parameters are well correlated. Although limited IMF observations indicate that the UT variations are related to variations in $B_{Z}$, a discussion of the cause of these variations is outside the scope of the present paper, which is to describe the spatial relationship between different ionospheric parameters.

In Figure 3 a similar plot for a less-disturbed day is shown. The general features follow the same trends as were seen in Figure 2, although both the current and the hightemperature contours on the average have moved several degrees poleward. Between 1100 and 1500 UT (magnetic local noon is at $1400 \mathrm{UT}$ ) it is not possible to locate a maximum in the electron temperature, presumably because it migrates poleward and out of the radar range.

On this day a clear velocity reversal could be found only on the postnoon side. This holds for most of the days we examined, and is due to the fact that $B_{y}$ (as inferred from the direction of the DPY current) was negative during most of the period.

Between 0950 and 1030 UT and between 1340 and 1640 UT we cauld not identify the lower and upper boundary respectively of the DPY current. This is indicated by omitting the solid line otherwise bordering the shaded area.

In order to get a quantitative measure of the correlation among the various parameters, we performed a linear correlation analysis. The resulting regression lines, each of which is based upon approximately $\mathbf{4 0}$ data points, are shown in Figure 4, where the upper and the lower boundary of the
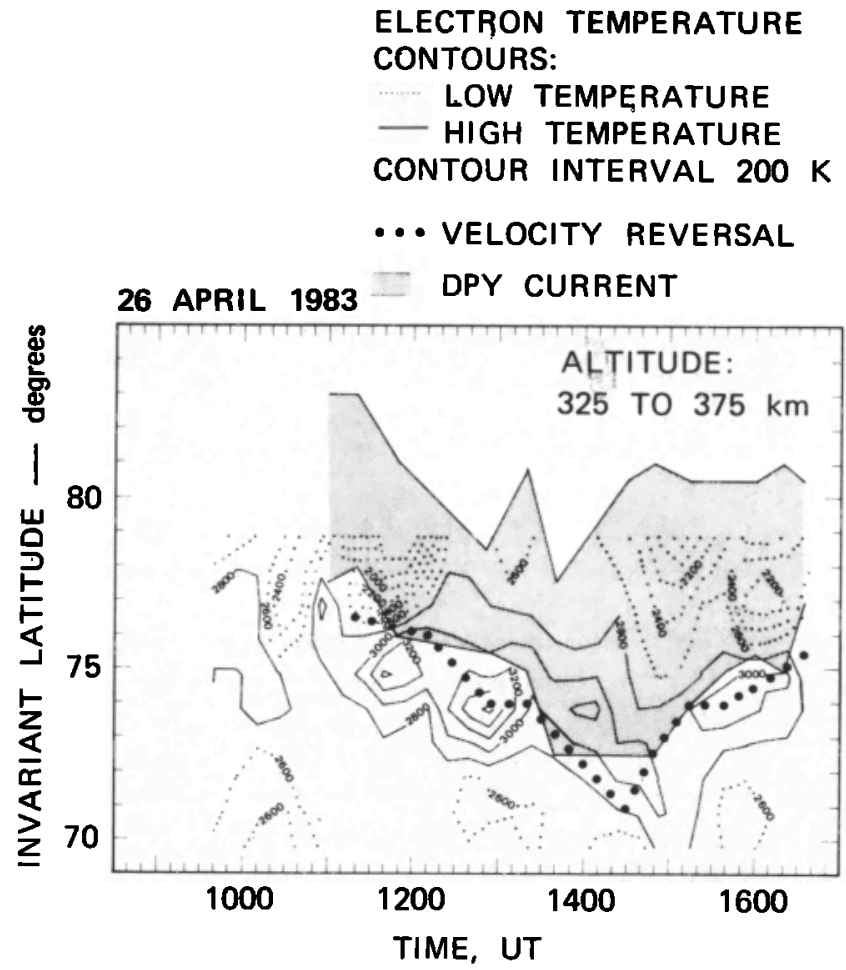

Fig. 2. Comparison of boundaries on the dayside at very high latitudes. The contours of electron temperature are from the altitude range $325-375 \mathrm{~km}$. The high temperature contours are drawn with solid lines while the low temperature contours are dotted. This highest contour is $3600 \mathrm{~K}$ and the contour interval is $200 \mathrm{~K}$. The shaded area shows the location of the DPY current, and the filled circles show the location of the convection reversal. Magnetic local noon is approximately $1400 \mathrm{UT}$. 


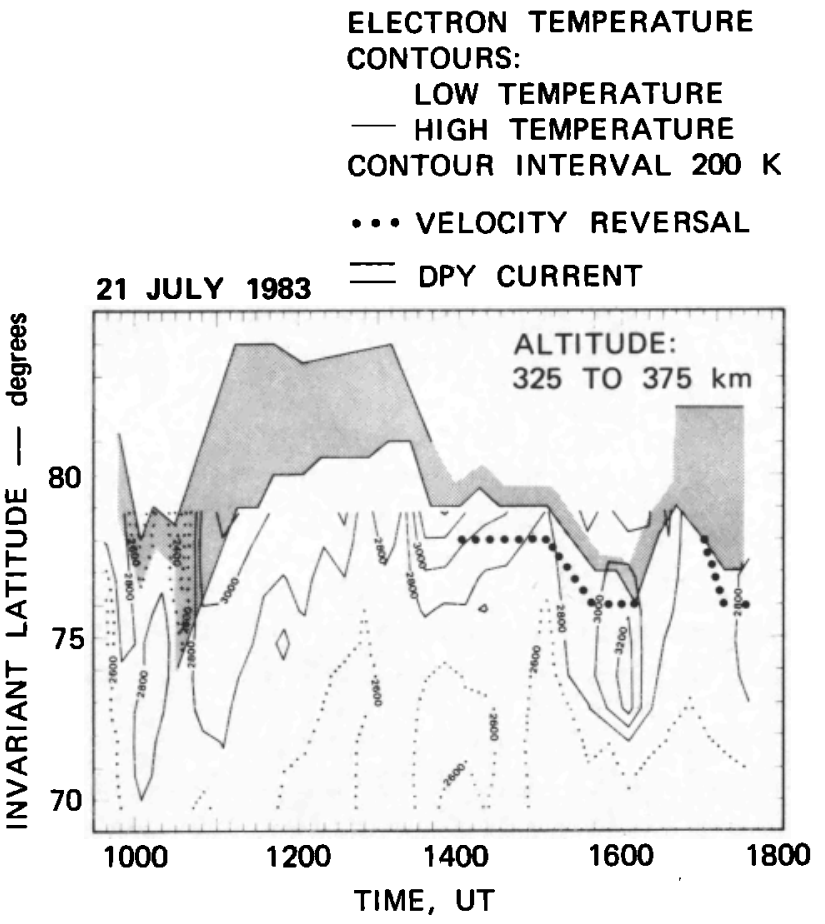

Fig 3. Same as Figure 2, but for a more quiet day. The highest electron temperature contour is $3200 \mathrm{~K}$.

DPY current and the velocity-reversal boundary are plotted against the latitude of the maximum in Te. The correlation coefficient $r$ is seen to be rather high. For the reversal boundary it is slightly above 0.8 and for the boundaries of the current it is around 0.7 . The slope of the regression lines is only slightly below 1.0. Because of the limited invariant



Fig. 4. Regression lines obtained by least squares fitting, showing the connection between the latitude of maximum Te, the velocity reversal, and the lower and upper boundary of the DPY current $r$ is the linear correlation coefficient latitude range of the radar, there are no data available when the Te maximum is above $79^{\circ} \Lambda$. The $2800 \mathrm{~K}$ contour lines of Figure 3 indicate, however, a good correlation even at these latitudes.

\section{Discussion}

The region of intense precipitation of soft, magnetosheathlike electrons in the dayside polar ionosphere is reported to have a rather well-defined latitudinal extent; especially the equatorward boundary is seen to stand out very clearly in satellite data [e.g., Burch, 1972]. The latitudinal width varies but it is often around $5^{\circ}$. Soft electron precipitation will heat the F-region plasma, and we therefore suggest that our observed regions of enhanced electron temperature spatially coincide with the regions of soft electron precipitation.

McDiarmid et al. [1976] found that hard electrons characteristic of closed field lines were present in the equatorward half of the region of soft electron precipitation. Candidi and Meng [1984] likewise concluded from simultaneous observations at conjugate points that the equatorward part of the region normally is on closed field lines mapping out to the low-latitude boundary layer (when present), while the poleward part is on open or tail field lines.

If one assumes that the region of elevated electron temperature and the region of soft electron precipitation are roughly coincident, the results of Figures 2 and 3 also show that the region is divided into two physically distinct parts. The boundary between primary and secondary convection passes right through this region, and the DPY current is located only in the poleward part. The auroral electrojets are not shown on Figures 2 and 3, but when they are present, they are located equatorward of the convection reversal and hence equatorward of the DPY current.

From our observations of currents and other ionospheric parameters we therefore conclude that the DPY current is physically associated with the primary convection, contrary to the electrojets, which are associated with the return flow. Furthermore the DPY current and the electrojets are flowing in two physically distinct regions; the DPY current is flowing in the polar cap on open field lines or field lines mapping out to the tail, while the auroral electrojets are flowing on closed field lines.

Another interesting feature is that the DPY current is not limited to the region of elevated electron temperature but penetrates deep into the polar cap. The DPY current is limited on the equatorward side by the cleft, whereas its poleward boundary has no obvious magnetospheric counterpart.

Acknowledgments. We thank the many people at the Danish Meteorological Institute, SRI International, and Stanford University who contributed to this research. The radar is operated by SRI International under NSF cooperative agreement ATM8121671. The research at SRI was supported by this cooperative agreement. The research at Stanford was supported by NSF grant ATM8210562.

\section{References}

Burch, J. L., Precipitation of low-energy electrons at high latitudes: Effects of interplanetary magnetic field and 
dipole tilt angle, J. Geophys. Res., 77, 6696-6707, 1972.

Candidi, M., and C.-I. Meng, Nearly simultaneous observations of the conjugate polar cusp regions, Planet. Space Sci., 32, 41-46, 1984.

Clauer, C. R., P. M. Banks, A. Q. Smith, T. S. Jorgensen, E. Friis-Christensen, S. Vennerstrom, V. B. Wickwar, J. D. Kelly, and J. Doupnik, Observation of interplanetary magnetic field and of ionospheric plasma convection in the vicinity of the dayside polar cleft, Geophys. Res. Lett., this issue, 1984.

Feldstein, Y. I., R. G. Afonina, B. A. Belov, and A. E. Levitin, Magnetic field and field-aligned current variations in the polar cusp controlled by interplanetary medium parameters, Planet. Space Sci., 30, 635-640, 1982.

Foster, J. C., J. R. Doupnik, and G. S. Stiles, Large scale patterns of auroral ionospheric convection observed with the Chatanika radar, J. Geophys. Res., 86, 11357-11371, 1981.

Friis-Christensen, E., and J. Wilhjelm, Polar cap currents for different directions of the interplanetary magnetic field in the Y-Z plane, J. Geophys. Res., 80, 1248-1260, 1975.

Friis-Christensen, E., High latitude ionospheric currents, in Exploration of the Polar Upper Atmosphere, edited by C. S. Deehr and J. A. Holtet, pp. 315-328, D. Reidel Publishing Company, Boston, Mass., 1981.

Friis-Christensen, E., Y. Kamide, A. D. Richmond, and S. Matsushita, Interplanetary magnetic field control of high-latitude electric fields and currents determined from Greenland magnetometer data, J. Geophys. Res., in press, 1984.

Iijima, T., and T. A. Potemra, The amplitude distribution of field-aligned currents at northern high latitudes observed by TRIAD, J. Geophys. Res., 81, 2165-2174, 1976.

Jorgensen, T. S., E. Friis-Christensen, V. B. Wickwar, J. D. Kelly, C. R. Clauer, and P. M. Banks, On the reversal from "sunward" to "antisunward" plasma convection in the dayside high latitude ionosphere, Geophys. Res. Lett., this issue, 1984.

Kamide, Y., The relationship between field-aligned currents and the auroral electrojets: A review, Space Sci. Rev., 31, 127-243, 1982.

Kisabeth, J. L., and G. Rostoker, Development of the polar electrojet during polar magnetic substorms, J. Geophys. Res., 76, 6815-6828, 1971.
McDiarmid, I. B., J. R. Burrows, and E. E. Budzinski, Particle properties in the dayside cleft, J. Geophys. Res., 81, 221-226, 1976.

McDiarmid, I. B., J. R. Burrows, and M. D. Wilson, Largescale magnetic field perturbations and particle measurements at $1400 \mathrm{~km}$ on the dayside, J. Geophys. Res., 84, 1431-1441, 1979.

Mishin, V. M., G. B. Shpynev, and A. D. Bazarzhapov, Large-scale electric field and currents in the high-latitude ionosphere and magnetosphere as a function of solar wind parameters, Adv. Space Res., 1, 159-169, 1981.

Rich, F. J., and Y. Kamide, Convection electron fields and ionospheric currents derived from model field-aligned currents at high latitudes, J. Geophys. Res., 88, 271-281, 1983.

Rostoker, G., Magnetospheric and ionospheric currents in the polar cusp and their dependence on the $\mathrm{B}_{\mathrm{y}}$ component of the interplanetary magnetic field, J. Geophys. Res., 85, 4167-4176, 1980.

Troshichev, O. A., Polar magnetic disturbances and fieldaligned currents, Space Sci. Rev., 32, 275-360, 1982.

Wickwar, V. B., and W. Kofman, Dayside red auroras at very high latitudes: The importance of thermal excitation, Geophys. Res. Lett., this issue, 1984.

Wickwar, V. B., J. D. Kelly, O. de la Beaujardière, C. A. Leger, F. Steenstrup, and C. H. Dawson, Sondrestrom overview, Geophys. Res. Lett., in press, 1984.

Wilhjelm, J., E. Friis-Christensen, and T. A. Potemra, The relationship between ionospheric and field-aligned currents in the dayside cusp, J. Geophys. Res., 83, 5586-5594, 1978.

S. Vennerstrom, E. Friis-Christensen, T. S. Jorgensen, O. Rasmussen, Division of Geophysics, Danish Meteorological Institute, Lyngbyvej 100, DK-2100 Copenhagen, Denmark. C. R. Clauer, STAR Laboratory, Stanford University, Stanford, CA 94305.

V. B. Wickwar, Radio Physics Laboratory, SRI International, 333 Ravenswood Avenue, Menlo Park, CA 94025.

(Received May 30, 1984; accepted June 19, 1984.) 